\title{
ORIGINAL ARTICLE High proportions of regulatory T cells in PBSC grafts predict improved survival after allogeneic haematopoietic SCT
}

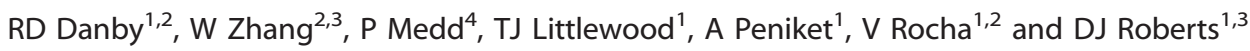

\begin{abstract}
Regulatory T cells (Tregs) modulate immune responses and improve survival in murine transplant models. However, whether the Treg content of allogeneic cell grafts influences the outcome in human haematopoietic stem cell (HSC) transplantation is not well established. In a prospective study of 94 adult allogeneic PBSC transplants (60\% unrelated; $85 \%$ reduced intensity conditioning), the median Treg $\left(\mathrm{CD}^{+} \mathrm{CD} 4^{+} \mathrm{CD} 25^{+} \mathrm{FOXP}^{+} \mathrm{CD} 127^{\mathrm{dim} /-}\right)$ dose transplanted was $4.7 \times 10^{6} / \mathrm{kg}$, with Tregs accounting for a median of $2.96 \%$ of $\mathrm{CD}^{+} \mathrm{T}$ cells. Patients transplanted with grafts containing a Treg/CD4 ${ }^{+} \mathrm{T}$-cell ratio above the median had a 3-year overall survival of $75 \%$, compared with $49 \%$ in those receiving grafts with a Treg/CD4 ${ }^{+}$T-cell ratio below the median $(P=0.02)$, with a 3 -year non-relapse mortality of $13 \%$ and $35 \%$, respectively $(P=0.02)$. In multivariate analysis, a high graft Treg/CD4 ${ }^{+} \mathrm{T}$-cell ratio was an independent predictor of lower non-relapse mortality (hazard ratio (HR), $0.30 ; P=0.02$ ), improved overall survival (HR, 0.45 ; $P=0.03)$ and improved sustained neutrophil (HR, 0.52; $P=0.002)$, platelet $(\mathrm{HR}, 0.51 ; P<0.001)$ and lymphocyte $(\mathrm{HR}, 0.54 ; P=0.009)$ recovery. These data support the hypothesis that the proportion of Tregs in allogeneic HSC grafts influences clinical outcome and suggest that Treg therapies could improve allogeneic HSC transplantation.
\end{abstract}

Bone Marrow Transplantation (2016) 51, 110-118; doi:10.1038/bmt.2015.215; published online 21 September 2015

\section{INTRODUCTION}

Allogeneic haematopoietic stem cell transplantation (HSCT) is a curative therapy for many haematological disorders. However, despite continued improvements, HSCT is associated with significant morbidity and mortality. ${ }^{1,2}$ In particular, the immunological disparity between donor and recipient can cause graft rejection or GvHD. ${ }^{3}$ T-cell depletion and systemic immunosuppressive therapy reduce the incidence and severity of these complications, but delay immune reconstitution and increase the risk of infection. ${ }^{4,5}$ Furthermore, these strategies impair the GvL response, increasing the risk of relapse. $^{6}$ Reducing the harmful immunological effects while sparing the GvL response could, therefore, improve HSCT outcomes.

Regulatory T cells (Tregs) have an important role in allogeneic HSCT. In animal models, cotransfer of $\mathrm{CD}^{+} \mathrm{CD} 25^{+}$Tregs and $\mathrm{CD} 4^{+} \mathrm{CD} 25^{-}$effector T cells into MHC-mismatched mice with leukaemia prevented lethal GvHD but allowed an effective GvL response. ${ }^{7,8}$ In humans, reduced $\mathrm{CD}^{+} \mathrm{CD} 25^{\text {high }}$ cells, $\mathrm{CD} 4^{+}$ $\mathrm{CD}_{2} 5^{\text {high }} \mathrm{FOXP}^{+}$cells and FOXP3 mRNA in blood and tissues have been observed in patients with $\mathrm{GvHD}^{9-13}$ whereas several strategies used to treat GvHD have been associated with in vivo Treg expansion. ${ }^{14-17}$ Early phase clinical trials of adoptive transfer of ex vivo isolated and expanded Tregs have also been commenced. ${ }^{18-20}$ However, few studies have examined the influence of Tregs in HSC grafts with clinical outcomes. In this study, we hypothesised that higher proportions of Tregs (Tregs/ $\mathrm{CD}^{+} \mathrm{T}$ cells) in PBSC grafts are associated with improved haematological, immunological and clinical outcomes following allogeneic HSCT.

\section{MATERIALS AND METHODS}

Patients

Ninety-four patients transplanted in Oxford (2009-2011) using allogeneic PBSC harvests were recruited (Table 1). Patients and donors were HLAmatched using high-resolution typing at HLA-A/B/C/DRB1/DQB1 (HLAmatched sibling $(n=37)$, single HLA-Ag-mismatched sibling $(n=1), 10 / 10$ unrelated donor $(n=39)$ and 9/10 unrelated donor $(n=17))$. GvHD prophylaxis was cyclosporin and methotrexate. Unrelated donor transplants also received alemtuzumab $60 \mathrm{mg}(30 \mathrm{mg}$ days $-8 /-7(n=49))$ or $90 \mathrm{mg}(30 \mathrm{mg}$ days $-8 /-7 /-6(n=7))$. Alemtuzumab $(60 \mathrm{mg})$ was also given in sibling transplants with a single HLA-mismatch $(n=1)$ or Hodgkin's disease $(n=1)$. Informed written consent was obtained in accordance with the Declaration of Helsinki. The study was approved by the Oxfordshire Research Ethics Committee $(07 / \mathrm{H} 0606 / 16)$ and Oxford University Hospitals NHS Trust.

\section{Flow cytometry}

Aliquots of G-CSF-stimulated PBSC grafts, with the total nucleated cell (TNC) and CD34 ${ }^{+}$dose, were obtained from the Stem Cell Laboratory (NHS Blood and Transplant, Oxford, UK). All samples were analysed fresh by flow cytometry (Figure 1 and Supplementary methods). Tregs $\left(\mathrm{CD}^{+} \mathrm{CD}^{+} \mathrm{CD} 8^{-}\right.$ $\mathrm{CD} 25^{+} \mathrm{FOXP3}^{+} \mathrm{CD} 127^{\mathrm{dim} /-}$ ) were expressed as the proportion of $\mathrm{CD}^{+}$ $T$ cells (Treg/CD4 ${ }^{+}$T-cell ratio) and dose $\left(\times 10^{6} / \mathrm{kg}\right)$.

\section{Outcomes}

Neutrophil, platelet and lymphocyte recoveries were defined as the first of three consecutive days with a count $>0.5,>50$ and $>1.0 \times 10^{9} / \mathrm{l}$, respectively, and recorded as sustained recovery in the absence of secondary graft failure. Acute GvHD (aGvHD) was graded using the Glucksberg criteria ${ }^{21,22}$ and chronic GvHD (cGvHD) using the Seattle criteria. ${ }^{23}$ CMV activation was defined as detection of CMV DNA by PCR. Relapse was recorded as disease recurrence and non-relapse mortality

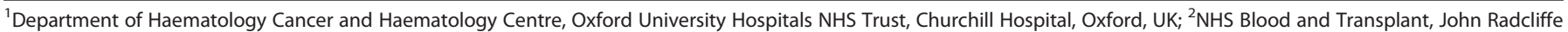

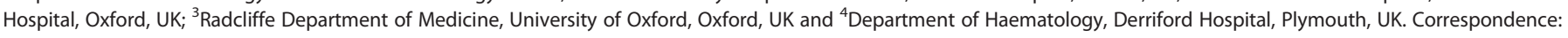
Dr RD Danby, Department of Haematology, Cancer and Haematology Centre, Oxford University Hospitals NHS Trust, Churchill Hospital, Oxford OX3 7LE, UK. 
Table 1. Patient, transplant and graft characteristics

\begin{tabular}{|c|c|c|}
\hline & Variable & $\mathrm{n}$ \\
\hline \multicolumn{3}{|l|}{ Recipient } \\
\hline Age (years) & Median (range) & $48(18-74)$ \\
\hline Gender & Male/female & $58 / 36$ \\
\hline CMV serology & Negative/positive & $48 / 46$ \\
\hline $\mathrm{ABO}$ & $\mathrm{O} / \mathrm{A} / \mathrm{B} / \mathrm{AB}$ & $40 / 37 / 8 / 9$ \\
\hline \multirow[t]{2}{*}{ Disease } & Acute leukaemia (AML/ALL) & $47(34 / 13)$ \\
\hline & Other (lymp/Mye/MDS) & $47(27 / 10 / 10)$ \\
\hline Disease status & Early/other & $46 / 48$ \\
\hline \multicolumn{3}{|l|}{ Donor } \\
\hline Age (years) & Median (range) & $40(19-72)$ \\
\hline Gender & Male/female & $64 / 30$ \\
\hline CMV serology & Negative/positive & $64 / 30$ \\
\hline $\mathrm{ABO}$ & $\mathrm{O} / \mathrm{A} / \mathrm{B} / \mathrm{AB}$ & $41 / 45 / 4 / 4$ \\
\hline \multicolumn{3}{|l|}{ Recipient/donor } \\
\hline Gender (R:D) & Male:female/other & $17 / 77$ \\
\hline CMV matching (R:D) & $-/-,-/+,+/-,+/+$ & $38 / 10 / 26 / 20$ \\
\hline ABO matching & $\begin{array}{l}\text { Matched/minor/major/ } \\
\text { bidirectional }\end{array}$ & $58 / 18 / 13 / 5$ \\
\hline HLA matching & $\begin{array}{l}\text { Matched/mM HvG/mM } \\
\text { GvH/mM Bi }\end{array}$ & $77 / 2 / 3 / 12$ \\
\hline \multicolumn{3}{|l|}{ Transplant } \\
\hline Donor & Sibling/unrelated & $38 / 56$ \\
\hline \multirow[t]{2}{*}{ Conditioning } & Myeloablative (CyTBI/BuCy) & $14(12 / 2)$ \\
\hline & Reduced intensity (FluMel/FluCy) & $80(79 / 1)$ \\
\hline Graft & PBSC/BM & $94 / 0$ \\
\hline Alemtuzumab & No/yes & $36 / 58$ \\
\hline PBSC graft & & $\times 10^{6} / \mathrm{kg}$ \\
\hline TNC & Median (range) & $1006(266-3762)$ \\
\hline $\mathrm{CD}_{3} 4^{+}$ & Median (range) & $6.3(1.1-19.8)$ \\
\hline $\mathrm{CD}^{+}$ & Median (range) & $280(87-801)$ \\
\hline $\mathrm{CD}^{+} \mathrm{CD}^{+}$ & Median (range) & $171(50-694)$ \\
\hline $\mathrm{CD}^{+}{ }^{+} \mathrm{CD} 8^{+}$ & Median (range) & $82(26-248)$ \\
\hline $\mathrm{CD} 19^{+}$ & Median (range) & $62(13-245)$ \\
\hline $\mathrm{CD}^{-} \mathrm{CD}^{-} 6^{+}$ & Median (range) & $35(8-101)$ \\
\hline Tregs & Median (range) & $4.7(0.8-20.6)$ \\
\hline Tregs/CD4 ${ }^{+} \mathrm{T}$ cells & Median (range) & $0.0296(0.008-0.086)$ \\
\hline \multicolumn{3}{|c|}{ 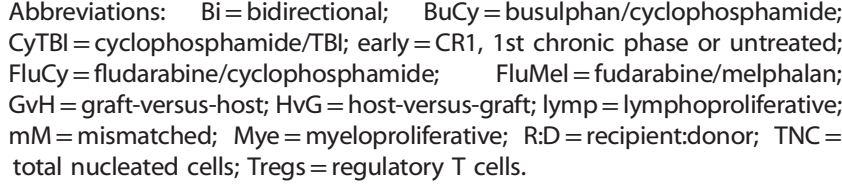 } \\
\hline
\end{tabular}

(NRM) was defined as death without relapse. Overall survival was from the day of transplantation to death or last follow-up.

\section{Statistics}

Categorical variables were tested using the $x^{2}$ test and continuous data using independent $t$-test or Mann-Whitney test. Correlations were analysed using Spearman's correlation. Backward linear regression was performed keeping variables with $P<0.05$. Overall survival was analysed using Kaplan-Meier. Cell recovery, GvHD, CMV, relapse and NRM were assessed using cumulative incidence with competing risk (relapse for NRM; death for other outcomes). Continuous variables were categorized using median or quartiles. Multivariate analysis was performed using the Cox proportional hazards (overall survival) or the Fine and Gray method (cumulative incidence). Variables with $P<0.10$ in univariate analysis were included and the model developed using a backward approach, keeping variables with $P<0.05$. As donor (sibling/unrelated) and alemtuzumab were strongly confounded, alemtuzumab was not included in analyses containing donor type. Statistical analysis was performed using SPSS 21
(IBM Corporation, New York, NY, USA) and R 3.0.2 (R Foundation for Statistical Computing, Vienna, Austria).

\section{RESULTS}

Graft composition

The median TNC and $\mathrm{CD}_{3} 4^{+}$cell dose transplanted was $10.1 \times$ $10^{8} / \mathrm{kg}$ (range, 2.7-37.6) and $6.3 \times 10^{6} / \mathrm{kg}$ (range, 1.1-19.8), respectively (Table 1 ). Tregs accounted for a median of $2.96 \%$ (range,

$0.81-8.56) \mathrm{CD}^{+} \mathrm{T}$ cells, with a median dose of $4.7 \times 10^{6} / \mathrm{kg}$ (range, 0.8-20.6). There were significant correlations between Treg dose and $\mathrm{TNC}, \mathrm{CD}^{+}, \mathrm{CD}_{1} 9^{+}$and $\mathrm{CD}^{-} \mathrm{CD}^{-} 6^{+}$dose $(P<0.0001)$ but not $\mathrm{CD}_{3} 4^{+}$cell dose (Supplementary Table S1). However, when Tregs were expressed as a proportion of $\mathrm{CD}^{+}{ }^{+} \mathrm{T}$ cells, there were no significant correlations with either $\mathrm{TNC}, \mathrm{CD} 34^{+}, \mathrm{CD}^{+}, \mathrm{CD}_{1} 9^{+}$or $\mathrm{CD}^{-} \mathrm{CD} 56^{+}$cell dose.

PBSC grafts from sibling donors contained higher numbers of Tregs (4.35 vs $\left.3.48 \times 10^{8} ; P=0.01\right)$ and higher Treg/CD4 ${ }^{+}$T-cell ratios $(0.033$ vs $0.026 ; P=0.04)$. PBSC harvests requiring a second day of collection contained higher numbers of TNC (996 vs $\left.753 \times 10^{8} ; P<0.0001\right), \mathrm{CD}^{+}\left(360\right.$ vs $\left.197 \times 10^{8} ; P<0.0001\right)$ and Tregs (6.76 vs $\left.3.51 \times 10^{8} ; P<0.0001\right)$, but lower $\mathrm{CD}^{+} 4^{+}$cells (4.47 vs $5.39 \times 10^{8} ; P=0.03$ ). However, Treg/CD4 ${ }^{+} \mathrm{T}$-cell ratios did not differ between 1 - and 2-day harvests $(P=0.74)$. Male donors showed an NS trend towards higher Treg/CD4 ${ }^{+} \mathrm{T}$-cell ratios $(P=0.07)$. There was no difference in Treg numbers or Treg/CD4 ${ }^{+}$T-cell ratios with donor age, ABO group or CMV serology. In multivariate analysis, the number of harvest days remained independently associated with Treg counts $(P<0.001)$. In contrast, male donors $(P=0.03)$ and sibling donors $(P=0.01)$ were independently associated with higher Treg/CD4 ${ }^{+}$ T-cell ratios.

To test the hypothesis that higher proportions of Tregs in the PBSC grafts are associated with improved outcomes following allogeneic HSCT, the study cohort was divided into two: above and below the median Treg/CD4 ${ }^{+}$T-cell ratio (Table 2). All multivariate analysis between Treg/CD4 ${ }^{+} \mathrm{T}$-cell ratio and outcomes was adjusted for significant differences between these groups (donor age and donor type).

\section{Neutrophil, platelet and lymphocyte recovery}

The cumulative incidence of neutrophil recovery (day 30) was $95 \%$ (95\% confidence intervals (95\% Cl): $87-98)$, with a median of 16 days (range, 11-32). Two patients with initial recovery had secondary graft failure (days 25 and 27) and received a second allogeneic HSCT. Patients receiving higher proportions of Tregs in the graft had a higher cumulative incidence of sustained neutrophil recovery (98\% (95\% Cl: 64-100) vs $87 \%(95 \% \mathrm{Cl}$ : 73-94); $P=0.046$ ) (Figure $2 a$ and Table 3 ). This remained significant (hazard ratio (HR), 0.55 (95\% Cl: 0.37-0.81); $P=0.003)$ when adjusting for significant differences between the groups. However, there was no significant difference in the incidence of neutrophil recovery when analysing Treg dose in the grafts $(P=0.71)$. In multivariate analysis, Treg/CD4 ${ }^{+}$T-cell ratio (HR 0.52 (95\% Cl: 0.37-0.79); $P=0.002)$ and $\mathrm{CD}^{+} 4^{+}$dose $(\mathrm{HR}, 0.65(95 \% \mathrm{Cl}$ : $0.44-0.96) ; P=0.03)$ were independent predictors of neutrophil recovery (Table 4 ).

The cumulative incidence of platelet recovery (day 60) was $94 \%$ (95\% Cl: 86-97), with a median of 13 days (range, 8-137). Patients receiving higher proportions of graft Tregs had a higher cumulative incidence of sustained platelet recovery (98\% (95\% Cl: $67-100)$ vs $87 \%(95 \% \mathrm{Cl}: 73-94) ; P=0.03)$, which remained significant after correcting for differences between the groups (HR, 0.54 (95\% Cl: 0.37-0.88); $P=0.002$ ) (Figure 2b). Treg dose was not associated with platelet recovery $(P=0.95)$. In multivariate analysis, the Treg/CD4 ${ }^{+}$T-cell ratio (HR, 0.51 (95\% Cl: 0.34-0.76); $\left.P<0.001\right)$ ), 

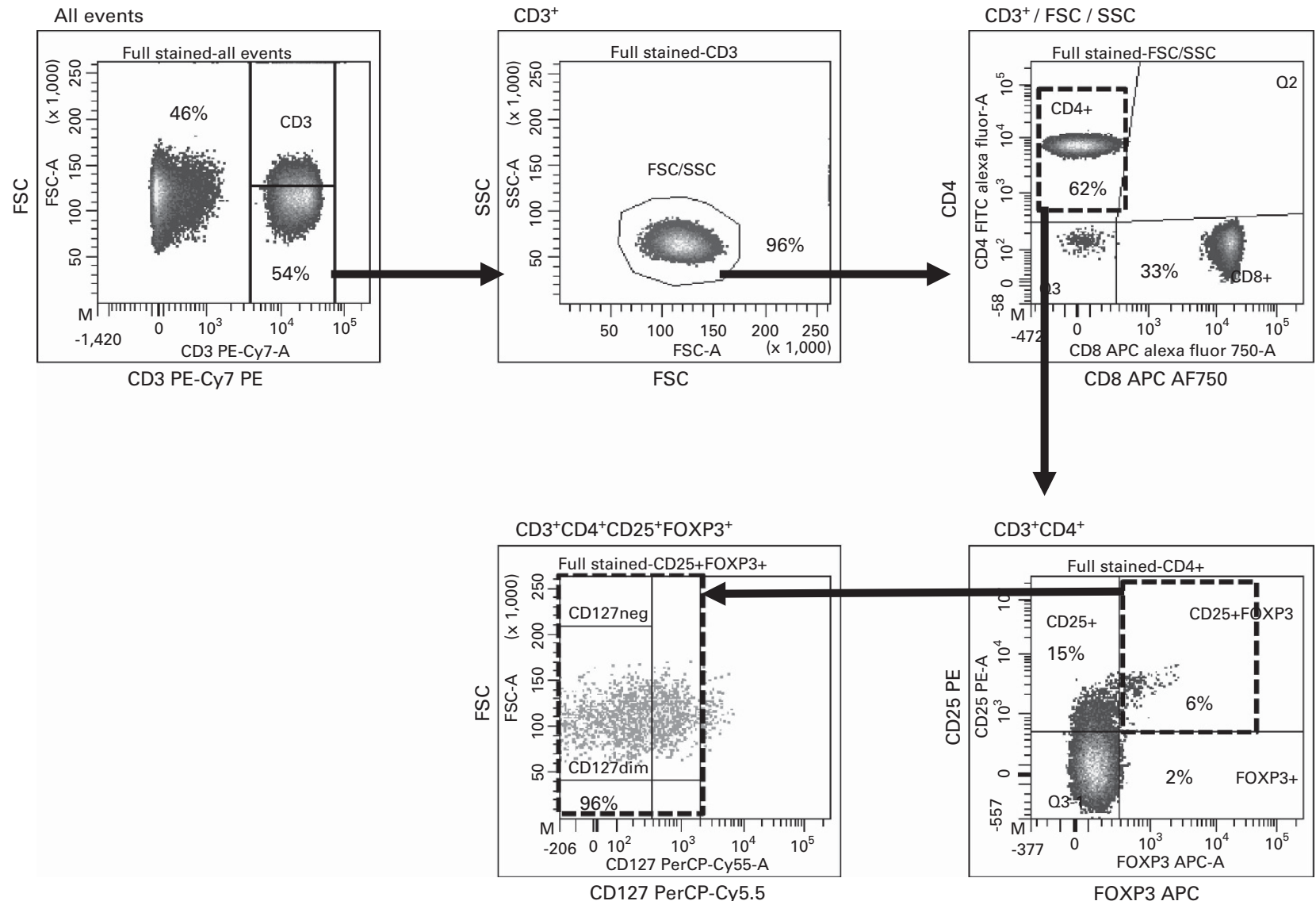

Figure 1. Flow cytometry for Tregs. PBMCs were stained with anti-CD3 PE-Cy7, -CD4 FITC, -CD8 APC-AF750, -CD25 PE, -FOXP3 APC, -CD127 PerCP-Cy5.5 and analysed on an LSRII Flow Cytometer (BD Biosciences, Oxford, UK). CD3 ${ }^{+}$cells were gated by CD3/FSC/SSC; CD3 ${ }^{+}$CD4 ${ }^{+}$CD $8^{-}$ cells analysed for FOXP3 and CD25 expression; $\mathrm{CD}^{+} \mathrm{CD}^{+} \mathrm{CD} 25^{+} \mathrm{FOXP} 3^{+}$cells analysed for expression of CD127. FSC, forward scatter; SSC, side scatter; Tregs, regulatory T cells.

$\mathrm{CD}^{+} 4^{+}$cell dose (HR, 0.60 (95\% Cl: $\left.\left.0.40-0.88\right) ; P=0.01\right)$ and $\mathrm{CD}^{-}$ $\mathrm{CD}^{+} 6^{+}$dose (HR 1.52 (95\% Cl: $\left.\left.1.01-2.27\right) ; \quad P=0.046\right)$ were independent predictors of platelet recovery (Table 4).

The cumulative incidence of lymphocyte recovery (6 months) was $72 \%$ (95\% Cl: $61-80)$, with a median of 99 days (range, 11-455). Patients receiving grafts containing higher than median Treg/CD4 ${ }^{+}$T-cell ratios had an increased incidence of lymphocyte recovery $(83 \%$ (95\% Cl: 68-92)) compared with those with lower than Treg/CD4 ${ }^{+}$T-cell ratios (61\% (95\% Cl: 45-73\%)) $(P=0.001)$ (Figure 2c). This was significant after adjusting for differences between the groups (HR, $0.56(95 \% \mathrm{Cl}$ : 0.35-0.88); $P=0.02)$. In multivariate analysis, higher Treg/CD4 ${ }^{+}$T-cell ratios $(\mathrm{HR}, 0.54$ (95\% Cl: 0.34-0.86); $P=0.009)$, sibling donors (HR, $0.30(95 \% \mathrm{Cl}$ : $0.16-0.55) ; \quad P<0.001)$ and female donors (HR, $0.59 \quad(95 \%$ Cl: 0.38-0.93); $P=0.02$ ) were independent predictors of improved lymphocyte recovery (Table 4).

\section{CMV activation}

CMV activation postHSCT was observed in 42 patients at a median of 22 days (range, $0-327$ ), with a cumulative incidence of $45 \%$ (95\% Cl: $35-55)$ at 1 year. Pretransplant positive CMV serology in the recipient $(P<0.001)$ and donor $(P<0.001)$, and the presence of an HLA-mismatch in the host-versus-graft ( $\mathrm{HvG}$ ) direction $(P=0.01)$ were associated with the risk of CMV activation. However, neither the Treg/CD4 ${ }^{+} \mathrm{T}$-cell ratio nor Treg dose in the graft were statistically significant $(P=0.89$ and $P=0.15$, respectively) (Figure 2d). In multivariate analysis, pretransplant
CMV seropositive status of the recipient (HR, $21.5 \quad(95 \% \mathrm{Cl}$ : 6.66-69.9); $P<0.001$ ) and donor (HR 2.50 (95\% Cl: 1.43-4.36); $P=0.001)$ remained independently associated with CMV activation (Table 4).

\section{GvHD}

The cumulative incidence grades II-IV and III-IV aGvHD was 31\% (95\% Cl: 22-40) and 15\% (95\% Cl: 9-23), respectively. The median onset for aGvHD (II-IV) was 27 days (range, 13-90). Single organ involvement was most frequent (61\%) but skin, gut and liver were involved in $9 \%$ of cases. The incidence of aGvHD (II-IV) fell short of statistical significance when analysing either the Treg/CD4 ${ }^{+} \mathrm{T}$-cell ratio $(P=0.11)$ or Treg dose $(P=0.11)$ in the graft (Figure 2e). In multivariate analysis, only disease status at transplant was a predictor of aGvHD (II-IV) (HR, 3.37 (95\% Cl: 1.48-7.66); $P=0.004)$ (Table 4). The cumulative incidence of $\mathrm{CGvHD}$ was $74 \%(95 \% \mathrm{Cl}$ : $63-82$ ) at 3 years, with an incidence of extensive cGvHD of $60 \%$ (95\% Cl: 48-70). Neither the Treg/CD4 ${ }^{+}$T-cell ratio $(P=0.79)$ nor Treg dose $(P=0.77)$ in the graft were associated with cGvHD (Figure 2f).

\section{Relapse and NRM}

Disease relapse occurred in 25 patients with a cumulative incidence at 3 years of $24 \%(95 \% \mathrm{Cl}$ : $16-33)$. There was no difference in the cumulative incidence of relapse when analysing either Treg/CD4 ${ }^{+}$T-cell ratios $(P=0.80)$ or Treg dose $(P=0.93)$ (Figure 3a). Patient diagnosis was associated with relapse 
Table 2. Baseline characteristics of the two study groups

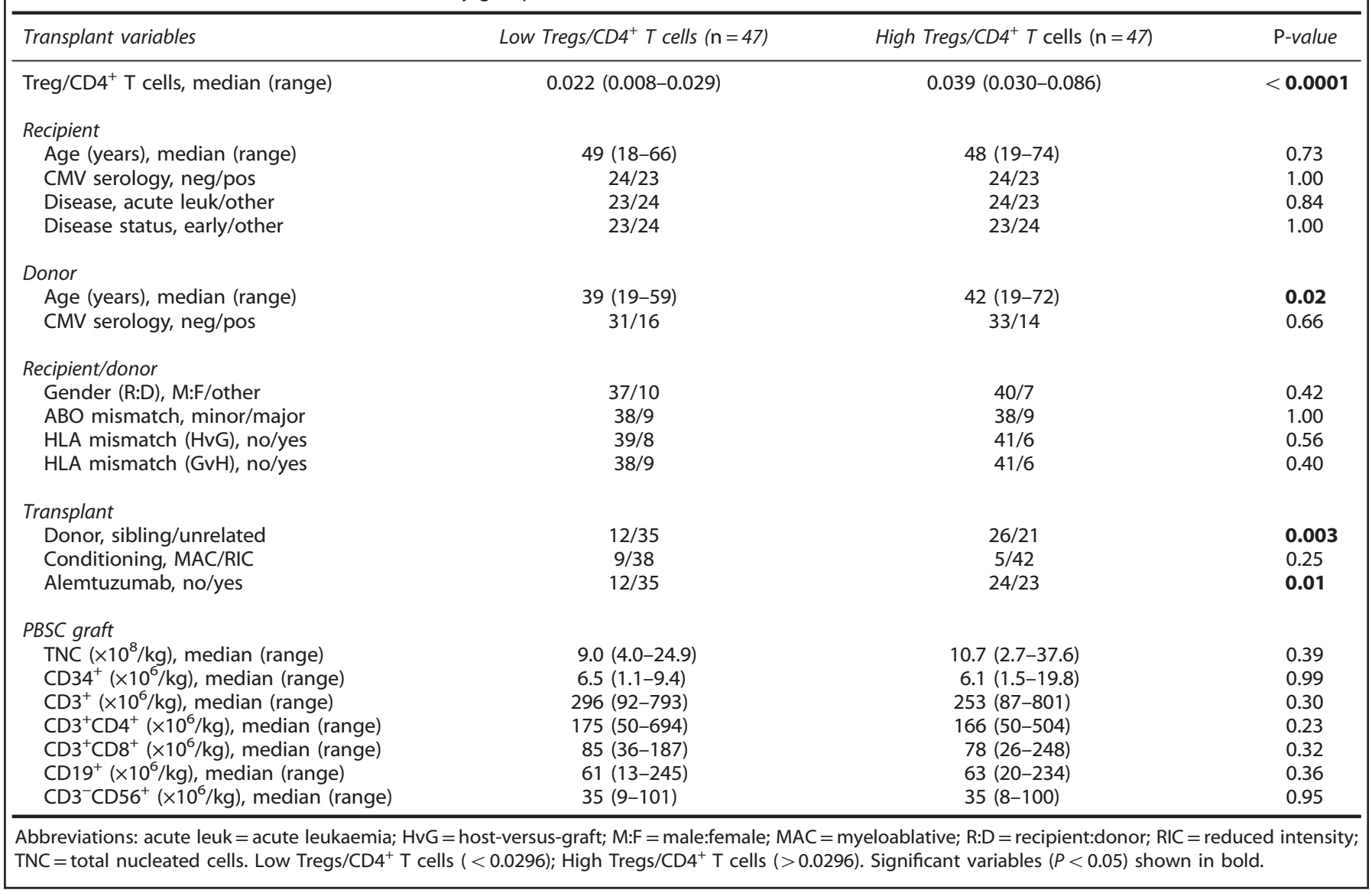

$(P=0.007)$, with a cumulative incidence of $34 \%(95 \% \mathrm{Cl}: 21-48)$ and $14 \%(95 \% \mathrm{Cl}: 6-27)$ for the acute leukaemia and other diagnoses, respectively. Diagnosis was the only independent predictor of relapse (HR, 3.54 (95\% Cl: 1.49-8.33); $P=0.004)$ (Table 4).

The 3-year cumulative incidence of NRM was $24 \%(95 \% \mathrm{Cl}$ : 16-33), with a median of 154 days (range, 10-747). GvHD was most frequent (45\%), followed by infection (27\%) (Table 5). Patients transplanted with PBSC grafts containing Treg/CD4 ${ }^{+} \mathrm{T}$-cell ratios below the median had a significantly higher NRM $(P=0.02)$, with a 3-year cumulative incidence of $35 \%(95 \% \mathrm{Cl}: 21-49)$ compared with $13 \%(95 \% \mathrm{Cl}: 5-24)$ in the remainder (Figure $3 \mathrm{~b})$. This remained significant after adjusting for differences between the groups ( $\mathrm{HR}, 3.32(95 \% \mathrm{Cl}$ : 1.18-9.35); $P=0.03)$. The observed increased incidence of NRM in patients transplanted with low Treg/CD4 ${ }^{+}$T-cell ratios in the graft was mainly because of increased late NRM ( $>100$ days) with a cumulative incidence at 3 years of $24 \%(95 \% \mathrm{Cl}: 13-37)$ and $4 \%(95 \% \mathrm{Cl}: 1-13)$, respectively $(P=0.006)$ (Supplementary Table S2). In comparison, the cumulative incidence of early NRM ( $<100$ days) did not differ between the low and high Treg/CD4 ${ }^{+}$T-cell groups, at $11 \%$ (95\% Cl: $2-22)$ and $9 \%(95 \% \mathrm{Cl}: 3-19)$, respectively $(P=0.73)$. Furthermore, the increased incidence of NRM in patients transplanted with low Treg/CD4 ${ }^{+}$T-cell ratios in the graft was principally because of increased mortality from GvHD. The 3-year cumulative incidence of mortality because of GVHD was $20 \%$ (95\% $\mathrm{Cl}: 10-32)$ and $2 \%(95 \% \mathrm{Cl}: 0-10)$, respectively $(P=0.007)$. In multivariate analysis, Treg/CD4 ${ }^{+}$T-cell ratio (HR, 0.30 (95\% Cl: $0.11-0.85) ; \quad P=0.02)$ and recipient CMV serology (HR, 3.41 (95\% Cl: 1.32-8.79); $P=0.01)$ remained independent predictors of NRM (Table 4).
Overall survival

The estimated overall survival at 3 years was $62 \%$ (95\% Cl: $53-72)$. Thirty-seven patients died at a median of 198 days (range, $10-1484)$. Patients transplanted with grafts containing Treg/CD4 ${ }^{+}$ T-cell ratios above the median had significantly better survival $(P=0.02)$, with 3 -year overall survival of $75 \%$ (95\% Cl: $63-88)$ compared with $49 \%$ (95\% Cl: 37-66) in the low Treg/CD4 ${ }^{+}$T-cell cohort (Figure 3c). This remained significant after adjusting for differences between groups (HR 0.48 (95\% Cl: 0.23-0.97); $P=0.04$ ). As with NRM, absolute Treg dose in the graft, was not associated with overall survival $(P=0.25)$. In multivariate analysis, high Treg/ $\mathrm{CD}^{+}$T-cell ratios in the graft (HR, 0.45 (95\% Cl: $\left.0.23-0.93\right)$; $P=0.03)$, younger recipient age (HR, 0.47 (95\% Cl: 0.23-0.98); $P=0.04)$ and negative recipient CMV serology ( $\mathrm{HR}, 0.45(95 \% \mathrm{Cl}$ : $0.23-0.88) ; \quad P=0.02$ ) were associated with improved overall survival (Table 4).

To demonstrate further the relationship between Tregs in the graft and survival, the study cohort was divided into quartiles using the Treg/CD4 ${ }^{+}$T-cell ratios (Figure $3 \mathrm{~d}$ and Supplementary Table S3). Overall survival at 3 years was $42 \%$ (95\% Cl: $26-67), 57 \%$ (95\% Cl: $40-81), 67 \%$ (95\% Cl: 50-89) and 83\% (95\% Cl: 69-100) for the first, second, third and fourth quartiles, respectively $(P=0.03)$. In multivariate analysis using the lowest quartile as the reference, patients transplanted with grafts containing the highest Treg/ $\mathrm{CD}^{+}{ }^{+}$T-cell ratios had significantly improved overall survival (HR, 0.22 (95\% Cl: 0.06-0.73); $P=0.01$ ).

\section{Subgroup analysis}

Owing to the potential confounding influence of donor type and alemtuzumab, subgroup analysis was performed for the T-replete 

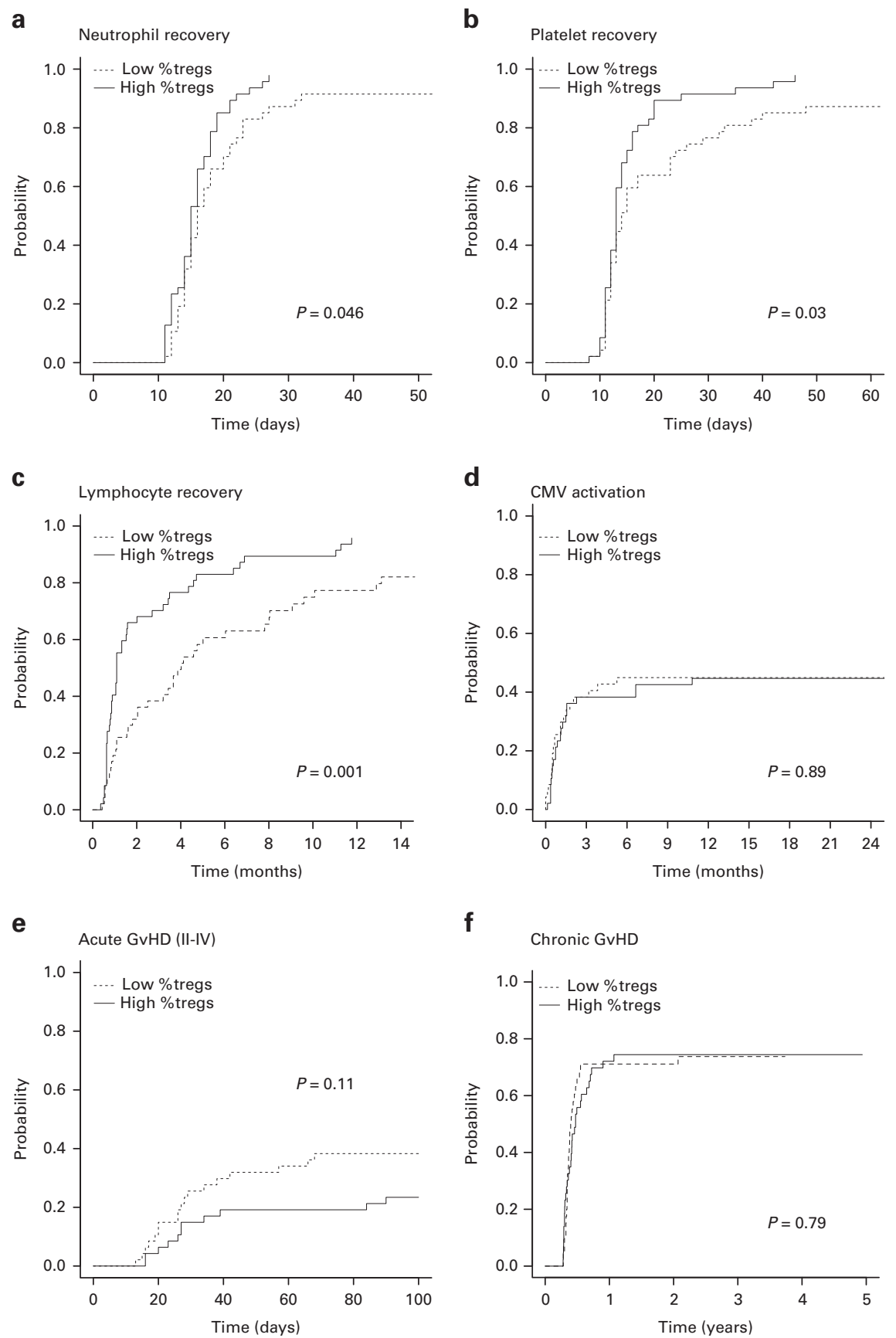

f

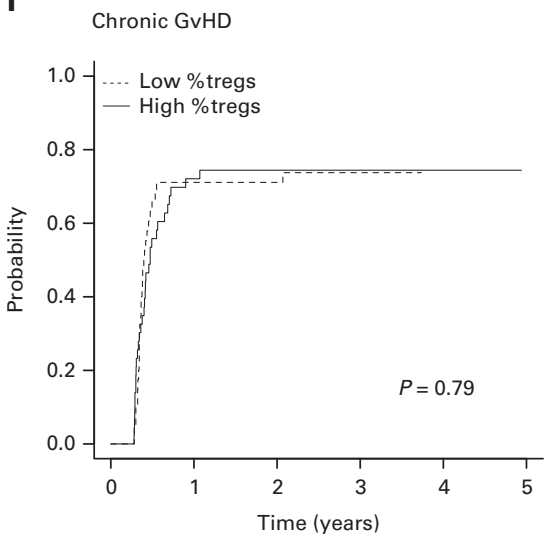

Figure 2. Haematopoietic recovery, CMV activation and GvHD. The cumulative incidence of (a) sustained neutrophil recovery $\left(>0.5 \times 10^{9} / \mathrm{l}\right)$, (b) sustained platelet recovery $\left(>50 \times 10^{9} / \mathrm{l}\right)$, (c) lymphocyte recovery $\left(>1.0 \times 10^{9} / \mathrm{I}\right)$, (d) CMV activation (CMV DNA detected by PCR), (e) acute GvHD (II-IV) and (f) chronic GvHD (all grades) according to the proportion of Tregs (Tregs/CD4 ${ }^{+}$T cells) in the graft. Low \%Tregs, Tregs/CD4 ${ }^{+}$ $\mathrm{T}$ cells below the median (dotted line); High \%Tregs, Tregs $/ \mathrm{CD}^{+}{ }^{\mathrm{T}}$ cells above the median (solid line); Tregs, regulatory $\mathrm{T}$ cells.

(no alemtuzumab) and T-deplete (alemtuzumab) transplants (Table 3). The association between Treg/CD4 ${ }^{+}$T-cell ratios in the graft above the median with improved neutrophil $(P=0.02)$, platelet $(P=0.02)$ and lymphocyte $(P=0.004)$ recovery remained significant in the T-deplete transplants. Conversely, an NS trend $(P=0.13)$ towards a lower incidence of acute GvHD (II-IV) with high Treg/CD4 ${ }^{+}$T-cell ratios was observed in T-replete transplants only. CMV reactivation and disease relapse were not significantly associated with the Treg/CD4 ${ }^{+}$T-cell ratio in the graft in either subgroup. The association between high Treg/CD4 ${ }^{+}$T-cell ratios in the graft with improved NRM and overall survival remained in the same direction for both the T-replete and T-deplete transplants, although not reaching statistical significance in these smaller subgroups. The 3-year overall survival in the alemtuzumabconditioned transplants was $48.6 \%(95 \% \mathrm{Cl}$ : 34.5-68.3) and 78.3\% (95\% Cl: 63.1-97.1) ( $P=0.07)(\mathrm{HR}, 0.44$ (95\% Cl: 0.17-1.10), $P=0.08)$ in the low and high Treg/CD4 ${ }^{+} \mathrm{T}$-cell groups, respectively (Supplementary Figure S1). Similarly, in the smaller T-replete cohort, the estimated 3-year overall survival was $50.0 \%(95 \% \mathrm{Cl}$ : 28.4-88.0) and 70.8\% (95\% Cl: 54.8-91.6) $(P=0.20)$ (HR $0.50(95 \%$ Cl: $0.17-1.49), P=0.21)$, respectively. 
Table 3. Univariate analysis

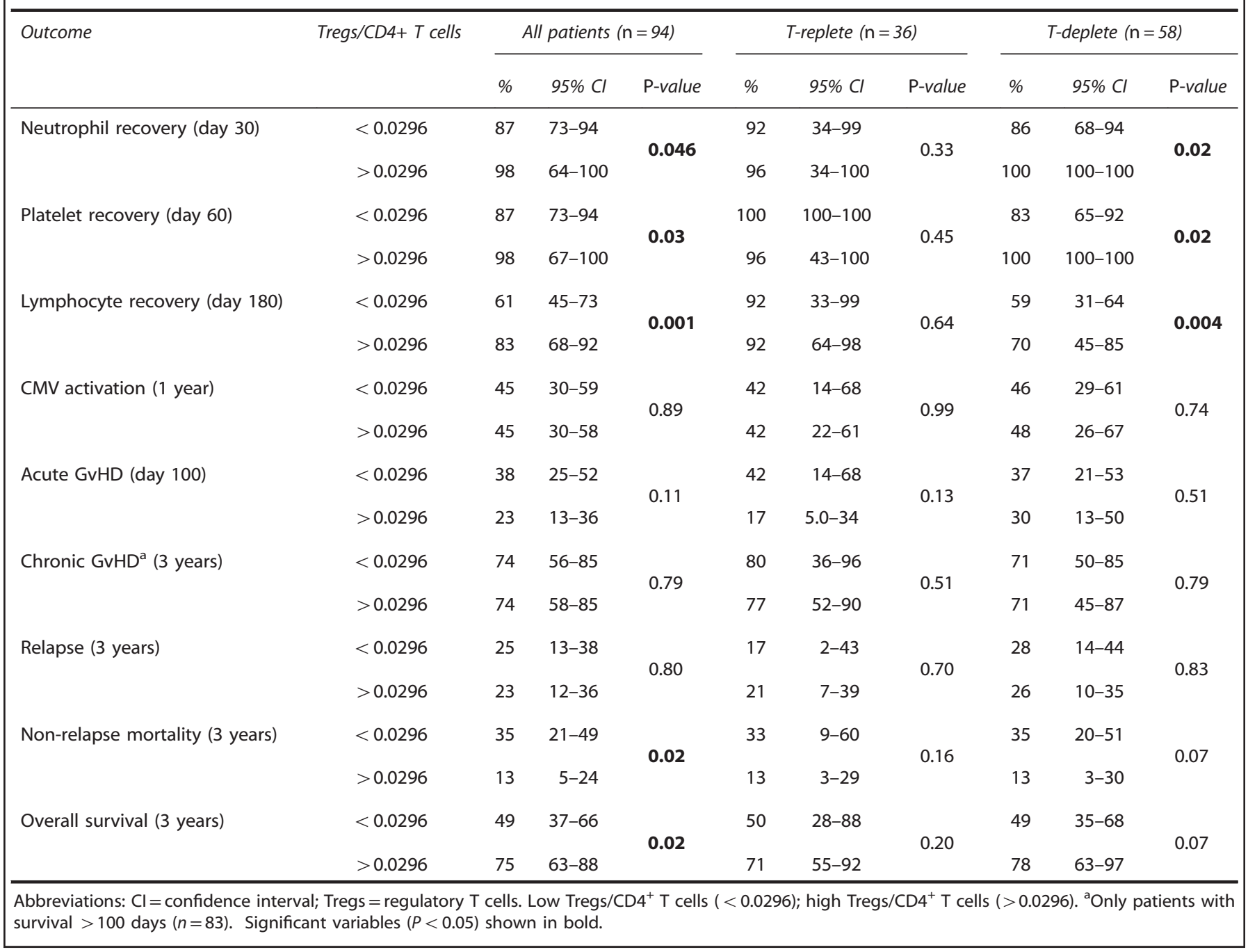

\section{DISCUSSION}

Our study of Tregs in PBSC grafts in allogeneic HSCT demonstrates that patients receiving higher proportions of Tregs have substantially better outcomes. Specifically, patients receiving grafts with Treg/CD4 ${ }^{+}$T-cell ratios above the median had a 3 -year overall survival of $75 \%$ compared with only $49 \%$ in the remainder $(P=0.02)$. This profound difference in survival was because of a reduction in NRM, with a 3 -year NRM of $13 \%$ and $35 \%$, respectively $(P=0.02)$. Our data showing that successive quartiles of increasing Treg/CD4 ${ }^{+}$T-cell ratios in the graft are associated with progressively better overall survival is consistent with a causal relationship. Furthermore, although not powered for formal subgroup analysis, our data suggest that the association between Treg/CD4 ${ }^{+}$T-cell ratios in the graft with NRM or survival may be observed both T-replete and T-deplete transplants.

What accounts for the improved NRM in patients receiving higher proportions of Tregs? Although less infective-related deaths were observed in patients receiving higher Treg/CD4 ${ }^{+}$ T-cell ratios, larger studies will be required to determine whether this is related to improved neutrophil and/or lymphocyte recovery and/or accounts for lower NRM. Nevertheless, the potential mechanisms accounting for the association between graft Treg/ $\mathrm{CD}^{+}{ }^{+}$-cell ratios and haematological recovery are intriguing. In mice, recipient Tregs residing in the bone marrow form a protective niche for transplanted allogeneic HSC, preventing HvG responses. ${ }^{24}$ Moreover, donor Tregs may also facilitate donor haematopoiesis and promote faster lymphocyte recovery by increasing HSC proliferation and cell cycling, possibly through the inhibition of conventional $\mathrm{CD}^{+} \mathrm{T}$ cells. ${ }^{25}$ Although, to our knowledge, no direct evidence for such an effect has been published in humans, our observational data suggest that Tregs may influence stem cell growth and development after HSCT. High proportions of Tregs in the graft may also aid immune tolerance, improving immune reconstitution during thymicindependent homeostatic expansion of mature donor $\mathrm{T}$ cells and/or thymic-dependent T-cell production. ${ }^{26-28}$ In our study, there was a trend towards less aGvHD and fewer deaths because of GvHD (1 vs 9 ) in patients receiving grafts with higher Treg/CD4 ${ }^{+}$ T-cell ratios, suggesting that that lower incidence of NRM in this group is due, at least in part, to reduced GvHD-related mortality.

Few clinical studies have examined the effect Tregs in allogeneic HSC grafts on transplant outcomes, although, the published evidence is consistent with our findings. Pastore et al. ${ }^{29}$ demonstrated, in 65 allogeneic HSC transplants, that a CD3/Treg ratio in the graft $>36$ was associated with an increased aGvHD. In an extended study $(n=74)$, the cohort with graft $C D 3 /$ Treg ratios $<36$ had improved 3-year overall survival ( $65 \%$ vs $31 \%$; $P=0.001)$ and lower NRM ( $5 \%$ vs $75 \% ; P<0.0001) .{ }^{30}$ There were 10 deaths from GvHD in the high CD3/Treg group, compared with just one in 
Table 4. Multivariate analysis

\begin{tabular}{|c|c|c|c|c|c|}
\hline \multirow{2}{*}{$\begin{array}{l}\text { Outcome } \\
\text { Neutrophil recovery }^{\mathrm{a}}\end{array}$} & \multicolumn{2}{|c|}{ Variable } & $\begin{array}{l}H R \\
0.52\end{array}$ & $\begin{array}{c}95 \% \mathrm{Cl} \\
0.37-0.79\end{array}$ & \multirow{2}{*}{$\begin{array}{c}\text { P-value } \\
0.002\end{array}$} \\
\hline & CD34 $4^{+}$dose & $>$Median & 0.65 & $0.44-0.96$ & \\
\hline \multirow{2}{*}{ Platelet recovery ${ }^{\mathrm{b}}$} & $\mathrm{CD} 4^{+}$dose & $>$Median & 0.60 & $0.40-0.88$ & 0.01 \\
\hline & $\mathrm{CD} 6^{+}$dose & > Median & 1.52 & $1.01-2.27$ & 0.046 \\
\hline Lymphocyte recovery $^{c}$ & Donor gender & Female & 0.59 & $0.38-0.93$ & 0.02 \\
\hline \multirow[t]{3}{*}{ CMV activation $^{d}$} & Tregs/CD4 ${ }^{+} \mathrm{T}$ cells & $>$ Median & 1.36 & $0.73-2.54$ & 0.33 \\
\hline & Recipient CMV & Seropositive & 21.5 & $6.66-69.9$ & $<0.001$ \\
\hline & Donor CMV & Seropositive & 2.50 & $1.43-4.36$ & 0.001 \\
\hline Acute $\mathrm{GvHD}^{\mathrm{e}}$ & Tregs/CD4 ${ }^{+} \mathrm{T}$ cells & > Median & 0.58 & $0.26-1.31$ & 0.19 \\
\hline Relapse $^{g}$ & Diagnosis & Leukaemia & 3.54 & $1.49-8.33$ & 0.004 \\
\hline \multirow[t]{2}{*}{ Non-relapse mortality ${ }^{\mathrm{h}}$} & Tregs/CD4 ${ }^{+} \mathrm{T}$ cells & $>$ Median & 0.30 & $0.11-0.85$ & 0.02 \\
\hline & Recipient CMV & Seropositive & 3.41 & $1.32-8.79$ & 0.01 \\
\hline \multirow[t]{3}{*}{ Overall survivali } & Tregs/CD4 ${ }^{+} \mathrm{T}$ cells & $>$ Median & 0.45 & $0.23-0.93$ & 0.03 \\
\hline & Recipient age & $>$ Median & 2.13 & $1.02-4.35$ & 0.04 \\
\hline & Recipient CMV & Seropositive & 2.22 & $1.14-4.35$ & 0.02 \\
\hline $\begin{array}{l}\text { Abbreviations: } \mathrm{Cl}=\text { confide } \\
\text { (Tregs/CD4 }{ }^{+} \mathrm{T} \text { cells) in the } \\
\text { type and alemtuzumab are } \\
\text { donor } \mathrm{CMV} \text { serology, HLA- } \\
\text { serology and HLA-mismat } \\
\text { shown in bold. }\end{array}$ & $\begin{array}{l}\mathrm{HR}=\text { hazard ratio; } \mathrm{Tr} \\
\text { ted for donor age a } \\
\text { l) and }{ }^{\mathrm{a}} \mathrm{CD} 34^{+} \text {cell d } \\
\text { HvG direction and } \\
\text { rection; 'Recipient a }\end{array}$ & MV serology & heas & $\begin{array}{l}\text { hodels wer } \\
\text { ab could } n \\
\text { reg dose; } \\
{ }^{\text {f None; }}{ }^{9} \mathrm{D} \\
\text { ion. Signif }\end{array}$ & $\begin{array}{l}n \text { of Tregs } \\
\text { as donor } \\
\text { serology } \\
\text { jent CMV } \\
(P<0.05)\end{array}$ \\
\hline
\end{tabular}

the low cohort. Other studies suggest a link between absolute Treg counts in allogeneic PBSC grafts and outcome. Wolf et al. ${ }^{31}$ showed an association between low Treg doses in the graft and aGvHD in 58 patients. Similarly, Pabst et al. ${ }^{32}$ showed that grafts with less than median Tregs had more aGvHD. ${ }^{32}$ These studies are, therefore, broadly consistent with our findings, although we suggest that the ratio of Tregs to other cells $\left(\mathrm{CD}^{+}{ }^{+}\right.$or $\mathrm{CD}^{+}{ }^{+} \mathrm{T}$ cells) in the graft is more likely to show an association with clinical outcomes than Tregs alone. Our data showing the association of Tregs $/ C D 4^{+} \mathrm{T}$ cells, but not Treg numbers, with outcomes supports this hypothesis. Furthermore, our findings are consistent with seminal work of Edinger et al. ${ }^{8}$ using adoptive transfer of T-cell subsets in mouse models of HSCT to show high Treg/CD4 ${ }^{+}$T-cell ratios permit a potent $\mathrm{GvL}$ response while reducing the clinical impact of aGvHD. ${ }^{8}$

The main limitation of our study is the size and heterogeneity of the study cohort and the confounding influence of donor type and alemtuzumab. This detailed phenotypic characterisation of donor grafts was only feasible at one centre, thus restricting the number of patients and dictating the population. However, a larger study would allow clarification of which donor factors influence Tregs in PBSC grafts. Interestingly, in this study, unrelated donors were associated with lower Treg/CD4 ${ }^{+}$T-cell ratios in the graft. Although the explanation remains unclear, it is speculated that the increased time between harvesting and flow cytometry analysis for the unrelated donor grafts may be associated with preferential loss of Tregs and/or downregulation of Treg phenotypic markers, for example, CD25 and/or FOXP3. A larger study would also address the question of whether the proportion of Tregs in the graft has an association with transplant outcomes across different clinical settings. In particular, it would allow predetermined subgroup analysis to confirm whether the influence of graft Tregs is significant in both T-deplete and T-replete transplants. Given the heterogeneity of our study cohort for diagnosis and conditioning regimen, the influence of donor Tregs on disease relapse also remains uncertain. A larger study may clarify whether higher proportions of donor Tregs in the graft reduce NRM, without adversely impacting on relapse, across different disease settings. Use of methylation-specific quantitative PCR to identify demethylated CpG loci within FOXP3, specific to Tregs, may simplify quantification of putative Tregs in these larger studies, while excluding transiently activated $\mathrm{FOXP3}^{+} \mathrm{T}$ cells. ${ }^{33}$

If confirmed by future studies, our observations that higher proportions of Tregs in donor PBSC grafts is associated with improved outcomes could have profound implications for HSCT. It may be speculated that selection of donors with higher peripheral blood Treg levels may provide PBSC grafts with higher proportions of Tregs. Alternatively, additional ex vivo isolation of Tregs could be used to increase the proportion of Tregs in the final HSC product. In keeping with this, Martelli et al. $^{20}$ reported a study of 43 patients receiving a haploidentical HSCT for acute leukaemia with coinfusion of ex vivo isolated Tregs. In the absence of posttransplant immunosuppression, adoptive immunotherapy with Tregs, produced high levels of engraftment and low incidence of acute GvHD and/or relapse compared with historical controls. Adoptive Tregs were also associated with improved lymphoid reconstitution and immunity to opportunistic infections. Whether these approaches improve survival compared with conventional methods and/or in the setting of HLA-matched transplants remains to be established. 
a

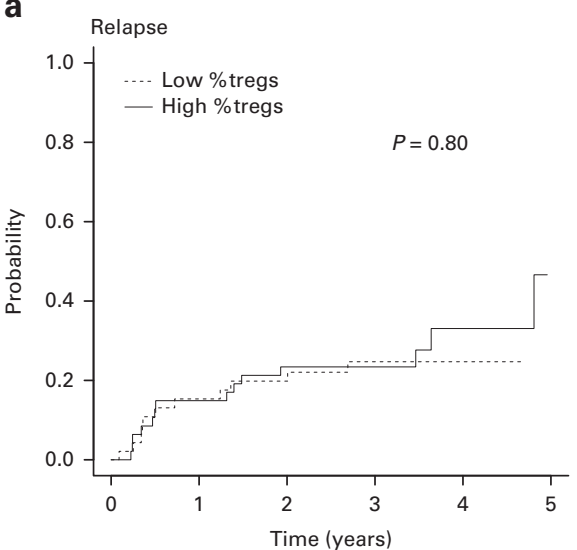

C

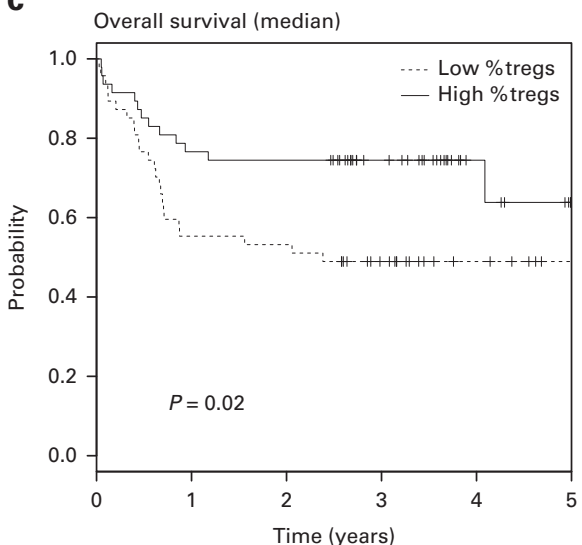

b

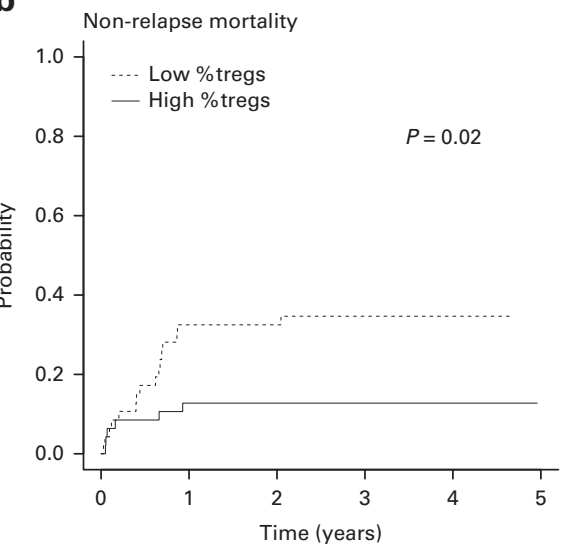

d

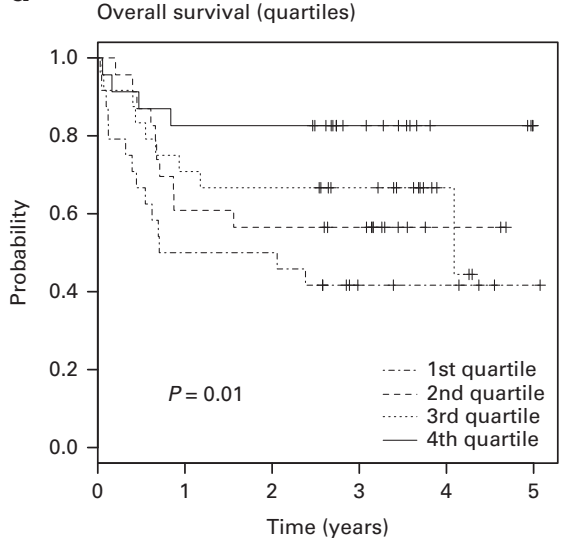

Figure 3. Relapse, NRM and overall survival. The cumulative incidence of (a) relapse and (b) NRM according to the proportion of Tregs (Tregs/ $\mathrm{CD} 4^{+} \mathrm{T}$ cells) in the graft. (c and d) Overall survival according to the proportion of Tregs (Tregs/CD4 ${ }^{+} \mathrm{T}$ cells) in the graft. (c) Low \%Tregs, Tregs/ $\mathrm{CD}^{+} \mathrm{T}$ cells below the median (dotted line); High \%Tregs, Tregs/CD4 ${ }^{+}$T cells above the median (solid line). (d) 1 st Quartile, Tregs/CD4 ${ }^{+} \mathrm{T}$ cells $<0.022 ;$ 2nd quartile, Tregs/CD4 ${ }^{+} \mathrm{T}$ cells $0.0223-0.0296 ; 3 \mathrm{rd}$ quartile, Tregs/CD4 ${ }^{+} \mathrm{T}$ cells $0.0297-0.0393 ;$ th quartile, Tregs/CD4 ${ }^{+} \mathrm{T}_{\text {cells }}$ $>0.0394$; Tregs, regulatory $\mathrm{T}$ cells.

Table 5. Cause of mortality

\begin{tabular}{|c|c|c|c|c|c|c|}
\hline \multirow[t]{2}{*}{ Cause } & \multicolumn{2}{|c|}{ All patients $(\mathrm{n}=94)$} & \multicolumn{2}{|c|}{ Low Tregs $/ C D 4^{+} T$ cells $(\mathrm{n}=47)$} & \multicolumn{2}{|c|}{ High Tregs $/ C D 4^{+} T(\mathrm{n}=47)$} \\
\hline & $\mathrm{n}$ & $\%$ & $\mathrm{n}$ & $\%$ & $\mathrm{n}$ & $\%$ \\
\hline Relapse & 15 & 41 & 8 & 33 & 7 & 54 \\
\hline Non-relapse & 22 & 59 & 16 & 66 & 6 & 46 \\
\hline GvHD & 10 & $27(45)$ & 9 & $38(56)$ & 1 & $8(17)$ \\
\hline
\end{tabular}

Abbreviations: Low Tregs/CD4 ${ }^{+}=$below the median $(<0.0296)$; High Tregs $/ C D 4^{+} \mathrm{T}=$ above the median $(>0.0296)$. Numbers within parentheses are the percentage of non-relapse mortality only.

In summary, our work shows a robust association between the proportion of Tregs in PBSC grafts and overall survival in allogeneic HSCT. These findings are supported by several other smaller studies. Large-scale, prospective studies of graft composition and outcome are imperative to determine the relationship between Tregs $/ C D 4^{+} \mathrm{T}$ cells in the grafts with clinical outcomes in different allogeneic HSCT settings. If high proportions of Tregs really are causally associated with lower NRM, it may be possible to manipulate Treg/CD4 ${ }^{+}$T-cell ratios in the graft or recipient to substantially improve survival.

\section{CONFLICT OF INTEREST}

The authors declare no conflict of interest.

\section{ACKNOWLEDGEMENTS}

We thank Prof Herman Waldman for his mentorship and valued support during this project; Oxford University Hospitals Bone Marrow Transplant team for helping with clinical data; and the Stem Cell Services Laboratory (NHSBT, Oxford, UK) for providing graft samples and clinical data. RD was supported by research funding from NHS Blood and Transplant (UK) and the Wellcome Trust Doctoral Training Fellowship 
Scheme for Clinicians (University of Oxford). The work was also, in part, supported by National Institute of Health Research (NIHR) (RP-PG-0310-1003) and the National Institute for Health Biomedical Research Centre Program at Oxford.

\section{AUTHOR CONTRIBUTIONS}

$\mathrm{RD}$ was involved in the study design, ethics application, execution, data analysis, drafting the article and producing the final article to be published. WZ supervised the laboratory work and reviewed the article. PM and TL were involved in clinical data collection and reviewing the article. VR supervised the data analysis, statistics and reviewed the article. AP was involved in the study design, ethics application, clinical data collection and supervised the study. DJR was involved in the study design, writing the article and supervised the study.

\section{REFERENCES}

1 Sorror M, Storer B, Sandmaier BM, Maloney DG, Chauncey TR, Langston A et al. Hematopoietic cell transplantation-comorbidity index and Karnofsky performance status are independent predictors of morbidity and mortality after allogeneic nonmyeloablative hematopoietic cell transplantation. Cancer 2008; 112: 1992-2001.

2 Gratwohl A, Stern M, Brand R, Apperley J, Baldomero H, de Witte T et al. Risk score for outcome after allogeneic hematopoietic stem cell transplantation: a retrospective analysis. Cancer 2009; 115: 4715-4726.

3 Welniak LA, Blazar BR, Murphy WJ. Immunobiology of allogeneic hematopoietic stem cell transplantation. Annu Rev Immunol 2007; 25: 139-170.

4 Chakraverty R, Orti G, Roughton M, Shen J, Fielding A, Kottaridis P et al. Impact of in vivo alemtuzumab dose before reduced intensity conditioning and HLAidentical sibling stem cell transplantation: pharmacokinetics, GVHD, and immune reconstitution. Blood 2010; 116: 3080-3088.

5 Schmidt-Hieber M, Schwarck S, Stroux A, Ganepola S, Reinke P, Thiel E et al. Immune reconstitution and cytomegalovirus infection after allogeneic stem cell transplantation: the important impact of in vivo T cell depletion. Int J Hematol 2010; 91: 877-885.

6 Soiffer RJ, Lerademacher J, Ho V, Kan F, Artz A, Champlin RE et al. Impact of immune modulation with anti-T-cell antibodies on the outcome of reducedintensity allogeneic hematopoietic stem cell transplantation for hematologic malignancies. Blood 2011; 117: 6963-6970.

7 Hoffmann P, Ermann J, Edinger M, Fathman CG, Strober S. Donor-type CD4+CD25 + regulatory $T$ cells suppress lethal acute graft-versus-host disease after allogeneic bone marrow transplantation. J Exp Med 2002; 196: 389-399.

8 Edinger M, Hoffmann P, Ermann J, Drago K, Fathman CG, Strober S et al. CD4 $+\mathrm{CD} 25+$ regulatory $\mathrm{T}$ cells preserve graft-versus-tumor activity while inhibiting graft-versus-host disease after bone marrow transplantation. Nat Med 2003; 9: 1144-1150.

9 Miura Y, Thoburn CJ, Bright EC, Phelps ML, Shin T, Matsui EC et al. Association of Foxp3 regulatory gene expression with graft-versus-host disease. Blood 2004; 104: 2187-2193.

10 Zorn E, Kim HT, Lee SJ, Floyd BH, Litsa D, Arumugarajah S et al. Reduced frequency of FOXP3+ CD4+CD25+ regulatory $T$ cells in patients with chronic graft-versus-host disease. Blood 2005; 106: 2903-2911.

11 Rezvani K, Mielke S, Ahmadzadeh M, Kilical Y, Savani BN, Zeilah J et al. High donor FOXP3-positive regulatory T-cell (Treg) content is associated with a low risk of GVHD following HLA-matched allogeneic SCT. Blood 2006; 108: 1291-1297.

12 Rieger K, Loddenkemper C, Maul J, Fietz T, Wolff D, Terpe $\mathrm{H}$ et al. Mucosal FOXP3+ regulatory $\mathrm{T}$ cells are numerically deficient in acute and chronic GvHD. Blood 2006; 107: 1717-1723.

13 Magenau JM, Qin X, Tawara I, Rogers CE, Kitko C, Schlough M et al. Frequency of CD4(+)CD25(hi)FOXP3(+) regulatory T cells has diagnostic and prognostic value as a biomarker for acute graft-versus-host-disease. Biol Blood Marrow Transplant 2010; 16: 907-914.

14 Gatza E, Rogers CE, Clouthier SG, Lowler KP, Tawara I, Liu C et al. Extracorporeal photopheresis reverses experimental graft-versus-host disease through regulatory T cells. Blood 2008; 112: 1515-1521.

15 Koreth J, Matsuoka K, Kim HT, McDonough SM, Bindra B, Alyea EP 3rd et al. Interleukin-2 and regulatory T cells in graft-versus-host disease. N Engl J Med 2011; 365: 2055-2066.
16 Matsuoka K, Koreth J, Kim HT, Bascug G, McDonough S, Kawano Y et al. Low-dose interleukin-2 therapy restores regulatory $T$ cell homeostasis in patients with chronic graft-versus-host disease. Sci Transl Med 2013; 5: 179 ra143.

17 Peccatori J, Forcina A, Clerici D, Crocchiolo R, Vago L, Stanghellini MT et al. Sirolimus-based graft-versus-host disease prophylaxis promotes the in vivo expansion of regulatory $\mathrm{T}$ cells and permits peripheral blood stem cell transplantation from haploidentical donors. Leukemia 2014; 29: 396-405.

18 Brunstein CG, Miller JS, Cao Q, McKenna DH, Hippen KL, Curtsinger J et al. Infusion of ex vivo expanded T regulatory cells in adults transplanted with umbilical cord blood: safety profile and detection kinetics. Blood 2011; 117: 1061-1070.

19 Edinger M, Hoffmann P. Regulatory T cells in stem cell transplantation: strategies and first clinical experiences. Curr Opin Immunol 2011; 23: 679-684.

20 Martelli MF, Di lanni M, Ruggeri L, Falzetti F, Carotti A, Terenzi A et al. HLA-haploidentical transplantation with regulatory and conventional T-cell adoptive immunotherapy prevents acute leukemia relapse. Blood 2014; 124: 638-644

21 Przepiorka D, Weisdorf D, Martin P, Klingemann HG, Beatty P, Hows J et al. 1994 Consensus Conference on Acute GVHD Grading. Bone Marrow Transplant 1995; 15: $825-828$.

22 Glucksberg H, Storb R, Fefer A, Buckner CD, Neiman PE, Clift RA et al. Clinical manifestations of graft-versus-host disease in human recipients of marrow from HL-A-matched sibling donors. Transplantation 1974; 18: 295-304.

23 Shulman HM, Sullivan KM, Weiden PL, McDonald GB, Striker GE, Sale GE et al. Chronic graft-versus-host syndrome in man. A long-term clinicopathologic study of 20 Seattle patients. Am J Med 1980; 69: 204-217.

24 Fujisaki J, Wu J, Carlson AL, Silberstein L, Putheti $\mathrm{P}$, Larocca $\mathrm{R}$ et al. In vivo imaging of Treg cells providing immune privilege to the haematopoietic stem-cell niche. Nature 2011; 474: 216-219.

25 Mueller AS, Poyser J, Kohrt HE, Shizuru JA. Conventional CD4+CD25 - and regulatory $\mathrm{CD} 4+\mathrm{CD} 25+\mathrm{T}$ cells have opposite effects on progenitor cells and hematopoietic reconstitution following stem cell transplantation. Blood 2014; 124: 654.

26 Gaidot A, Landau DA, Martin GH, Bonduelle O, Grinberg-Bleyer Y, Matheoud D et al. Immune reconstitution is preserved in hematopoietic stem cell transplantation coadministered with regulatory T cells for GVHD prevention. Blood 2011; 117: 2975-2983.

27 Clave E, Busson M, Douay C, Peffault de Latour R, Berrou J, Rabian C et al. Acute graft-versus-host disease transiently impairs thymic output in young patients after allogeneic hematopoietic stem cell transplantation. Blood 2009; 113: 6477-6484.

28 Di lanni M, Falzetti F, Carotti A, Terenzi A, Castellino F, Bonifacio E et al. Tregs prevent GVHD and promote immune reconstitution in HLA-haploidentical transplantation. Blood 2011; 117: 3921-3928.

29 Pastore D, Delia M, Mestice A, Carluccio P, Perrone T, Gaudio F et al. CD3+/Tregs ratio in donor grafts is linked to acute graft-versus-host disease and immunologic recovery after allogeneic peripheral blood stem cell transplantation. Biol Blood Marrow Transplant 2012; 18: 887-893.

30 Delia M, Pastore D, Mestice A, Carluccio P, Perrone T, Gaudio F et al. Outcome of allogeneic peripheral blood stem cell transplantation by donor graft CD3+/Tregs ratio: a single-center experience. Biol Blood Marrow Transplant 2013; 19: 495-499.

31 Wolf D, Wolf AM, Fong D, Rumpold H, Strasak A, Clausen J et al. Regulatory T-cells in the graft and the risk of acute graft-versus-host disease after allogeneic stem cell transplantation. Transplantation 2007; 83: 1107-1113.

32 Pabst $C$, Schirutschke $H$, Ehninger G, Bornhauser M, Platzbecker U. The graft content of donor $T$ cells expressing gamma delta TCR+ and CD4+foxp3+ predicts the risk of acute graft versus host disease after transplantation of allogeneic peripheral blood stem cells from unrelated donors. Clin Cancer Res 2007; 13: 2916-2922.

33 Baron U, Floess S, Wieczorek G, Baumann K, Grutzkau A, Dong J et al. DNA demethylation in the human FOXP3 locus discriminates regulatory $T$ cells from activated FOXP3(+) conventional T cells. Eur J Immunol 2007; 37: 2378-2389.

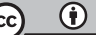

This work is licensed under a Creative Commons Attribution 4.0 International License. The images or other third party material in this article are included in the article's Creative Commons license, unless indicated otherwise in the credit line; if the material is not included under the Creative Commons license, users will need to obtain permission from the license holder to reproduce the material. To view a copy of this license, visit http://creativecommons.org/licenses/by/ $4.0 /$

Supplementary Information accompanies this paper on Bone Marrow Transplantation website (http://www.nature.com/bmt) 